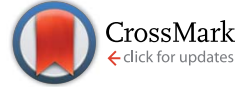

Cite this: RSC Adv., 2017, 7, 10143

Received 15th December 2016 Accepted 21st January 2017

DOI: 10.1039/c6ra28228h

rsc.li/rsc-advances

\title{
Polypyrrole-modified CuS nanoprisms for efficient near-infrared photothermal therapy $\dagger$
}

\author{
Ruiyang Zhao, ${ }^{b}$ Xiaoxia Sun, ${ }^{a}$ Jing Sun, ${ }^{a}$ Lei Wang ${ }^{a}$ and Jishu Han*a
}

The application of functional nanomaterials in cancer therapy has become a new developing trend due of their unique size-dependent physicochemical performance. In this study, CuS nanoprisms were fabricated via a seed-mediated growth method. The as-prepared CuS nanoprisms possessed a more intense nearinfrared absorption at $1184 \mathrm{~nm}$ compared with other morphologies. CuS nanoprisms were modified with a polypyrrole (PPy) shell on the surface through oxidative polymerization. The PPy shell efficiently decreased the nanocomposite cytotoxicity and increased the biocompatibility. Based on the excellent photothermal conversion performance of CUS-PPy nanoprisms, the cancer cells in vitro could be killed effectively and the tumor in vivo could be cured through photothermal therapy. This indicated that CuSPPy nanoprisms are able to be used as an efficient theranostic agent for tumor photothermal therapy in the future.

\section{Introduction}

To date, the major therapeutic approaches to fight against cancers include surgical resection, chemotherapy and radiotherapy. However, these approaches also lead to the damaging of healthy tissues, adverse reactions, and the occurrence of second cancers. ${ }^{1-3}$ With swift technical development, various diagnosis and therapy technologies are being explored and have the potential to offer optimum solutions to assist cancer management. ${ }^{4}$ Among them, photothermal therapy, as an emerging technique for cancer therapies, has attracted increasing attention recently. ${ }^{5-9}$ Utilizing inorganic nanoparticles with near-infrared (NIR) absorption and the photothermal conversion property as that of therapeutic agents, photothermal therapy can efficiently induce cancer cell death through near-infrared light irradiation, which is a noninvasive penetration and less harmful to healthy tissues than surgical resection, chemotherapy, and radiotherapy. ${ }^{10-14}$

In comparison, gold nanomaterials possess the NIR absorption property but are expensive. Carbon nanomaterials

${ }^{a}$ Key Laboratory of Eco-chemical Engineering, Ministry of Education, College of Chemistry and Molecular Engineering, Qingdao University of Science and Technology, Qingdao 266042, P. R. China. E-mail: jishu_han@163.com

${ }^{b}$ College of Chemical Engineering, Qingdao University of Science and Technology, Qingdao 266042, P. R. China

$\dagger$ Electronic supplementary information (ESI) available: TEM images of CuS nanomaterials synthesized through the seed-mediated process, XRD pattern of CuS-PPy nanoprisms, photographs of CuS-PPy nanoprisms and SDS-capped CuS nanoprisms stored in water, saline and PBS solution, temperature elevation of CuS-PPy nanoprisms during five cycles of on-and-off laser irradiation and UV-Vis-NIR spectra of CuS-PPy nanoprisms before and after five cycles of laser irradiation, cytotoxicity of SDS-capped CuS nanoprisms, the temperature rise profiles at the tumor site under laser irradiation with CuS-PPy or PBS. See DOI: $10.1039 / \mathrm{c} 6 \mathrm{ra} 28228 \mathrm{~h}$ show synergistic effect but low photothermal conversion efficiency. ${ }^{15}$ Copper chalcogenides, as a typical p-type semiconductor, has shown great potential in photothermal therapy. ${ }^{16,17}$ Since the high concentration of free carriers benefits the localized surface plasmon resonances (LSPRs), arising from excess holes in the valence band, copper chalcogenide possesses strong NIR absorption in the second NIR window $(\lambda=1000-1350 \mathrm{~nm})$ and efficiently photothermal conversion performance. ${ }^{18-21}$ CuS nanomaterials, as the most promising chalcogenides with potential applications in NIR photothermal therapy, bioimaging, and biosensing, ${ }^{22-26}$ have been synthesized with various morphologies, such as nanoparticles, nanorods, nanotubes, nanowires, nanoplates and nanoflowers. ${ }^{27-39}$ It was reported that the nanostructures with high aspect ratio or tips, such as triangular nanoplate, could lead to intense electromagnetic field localization effects and provide sufficiently distinct plasmon resonance in the NIR region..$^{40-47}$ Therefore, triangular CuS nanostructure would be a desired structure for NIR photothermal therapy application. A current challenge is tuning the morphology of CuS with efficient absorption of NIR wavelengths as well as controlling the toxicity for biological applications.

The synthesis methods for CuS nanomaterials have been reported including thermolysis, template-assisted growth, microwave irradiation, electrodeposition, hydrothermal or solvothermal methods and chemical vapor reaction. ${ }^{48-52}$ In comparison, the seed-mediated growth could realize CuS controllable preparation with smaller size and stronger shape anisotropy, possessing efficient NIR absorption. Generally the structure and property of CuS synthesized in the organic phase are better than those in aqueous phase. However, organic CuS is not directly applied in photothermal therapy. Further phase transformation should be used to obtain hydrophilic nanomaterials. To increase the stability and 
decrease the cytotoxicity, nontoxic polypyrrole (PPy) was selected to envelope the surface. ${ }^{53,54}$ Based on its good biocompatibility, PPy are reported to coat on the surface of inorganic nanoparticles like $\mathrm{Au}, \mathrm{Fe}_{3} \mathrm{O}_{4}{ }^{9,55,56}$ Moreover, PPy possesses good photostability and NIR absorption, which can improve the photothermal conversion efficiency of nanocomposites and benefit photothermal therapy. ${ }^{57,58}$ Pure PPy nanoparticles with various morphologies were reported to be applied in photothermal therapy. ${ }^{59,60}$ Therefore, the integration of CuS and PPy would effectively improve the biocompatibility of CuS as well as the NIR photothermal conversion efficiency in the NIR-II region. Based on our previous study of synthesizing various nanocomposites, in this study, we report the synthesis of PPy-modified CuS nanoprisms as a theranostic agent for photothermal therapy. Herein, CuS nanoprisms were synthesized by seed-mediated growth for two cycles to obtain an excellent NIR absorption property. The surface modification of PPy effectively improved the structure stability and biocompatibility. The CuS-PPy nanoprisms exhibited good photothermal conversion performance and effective cancer photothermal therapy.

\section{Experimental}

\section{Materials}

Copper(II) nitrate $\left(\mathrm{Cu}\left(\mathrm{NO}_{3}\right)_{2}, 99 \%\right)$, sulfur powder (99.5\%), oleylamine $\left(\mathrm{C}_{18} \mathrm{H}_{35} \mathrm{NH}_{2}, 90 \%\right)$, pyrrole (99\%, Acros), 1-octadecene $\left(\mathrm{C}_{18} \mathrm{H}_{36}, 95 \%\right)$, sodium dodecyl sulphate (SDS, 99\%), ammoniumperoxydisulfate $\left(\left(\mathrm{NH}_{4}\right)_{2} \mathrm{~S}_{2} \mathrm{O}_{8}, 98 \%\right)$, ethanol $\left(\mathrm{C}_{2} \mathrm{H}_{5} \mathrm{OH}\right.$, 99.7\%), chloroform $\left(\mathrm{CHCl}_{3}, 99 \%\right)$ and all the other chemicals used were commercially available products and purchased from the Beijing Chemical Factory, China. Dulbecco's Modified Eagle's Medium (DMEM, HyClone) and fetal bovine serum (FBS) were purchased from Gibco.

\section{Synthesis of CuS nanoprisms}

The synthesis of aqueous CuS nanoprisms followed the standard seed-mediated growth method. ${ }^{61}$ In brief, $48.3 \mathrm{mg}$ copper nitrate was dissolved into $1 \mathrm{~mL}$ oleylamine and $3 \mathrm{~mL}$ 1-octadecene mixed solution. Furthermore, $9.6 \mathrm{mg}$ sulfur powder was added into the copper nitrate solution and the mixture was stirred for $10 \mathrm{~min}$. Then, the mixture was placed in an oil bath at $140{ }^{\circ} \mathrm{C}$, which rapidly turned to dark brown. The mixture was held at that temperature for $45 \mathrm{~min}$ and then was finally cooled to room temperature. The synthesized CuS nanoparticles were washed with ethanol, centrifuged to remove oleylamine and 1octadecene, re-dispersed in chloroform and centrifuged to remove the byproducts. The synthesized CuS nanoparticles were used as a seed to dissolve in 1-octadecene.

The growth solution was prepared by dissolving $8.5 \mathrm{mg}$ copper nitrate in $0.25 \mathrm{~mL}$ oleylamine and $3.75 \mathrm{~mL}$ 1-octadecene mixed solution. Then, one tenth of the seed solution was added into the growth solution and stirred in an oil bath at $120{ }^{\circ} \mathrm{C}$ for $60 \mathrm{~min}$. The blue solution turned to a dark brown solution and was finally cooled to room temperature. The synthesized CuS nanoparticles were washed with ethanol, centrifuged to remove oleylamine and 1-octadecene, re-dispersed in chloroform and centrifuged to remove the byproducts. The grown CuS nanoparticles were used as the seed for the next growth, and the CuS nanoprisms were obtained through two growth cycles.

\section{Phase transfer of CuS nanoprisms}

$0.5 \mathrm{~mL}$ CuS nanoprisms chloroform solution was mixed with $5 \mathrm{~mL}$ of aqueous solution of $20 \mathrm{mg}$ SDS with vigorous stirring. At the same time, the mixture was heated to $80{ }^{\circ} \mathrm{C}$ to evaporate chloroform. After removing the chloroform, the mixture was cooled to the room temperature and centrifuged to remove free SDS. Then, aqueous SDS-capped CuS nanoprisms were obtained.

\section{Synthesis of PPy-modified CuS nanoprisms}

$5 \mathrm{~mL}$ aqueous solution of SDS-capped CuS nanoprisms was added with $300 \mu \mathrm{L}$ of $10 \mathrm{mM}$ pyrrole aqueous solution with vigorous stirring. Then, $1.5 \mathrm{~mL}$ of $2 \mathrm{mM}\left(\mathrm{NH}_{4}\right)_{2} \mathrm{~S}_{2} \mathrm{O}_{8}$ solution was added. The reaction mixture was stirred at room temperature for $12 \mathrm{~h}$ to ensure complete polymerization. The PPymodified CuS nanoprisms were purified by washing and centrifuging three times.

\section{Cytotoxicity and photothermal conversion assay}

The cytotoxicity of CuS-PPy nanoprisms was tested using a standard MTT assay. Human gastric cancer cell line MGC-803 cells were maintained in DMEM containing 10\% (vol/vol) FBS and $100 \mathrm{U} \mathrm{mL}{ }^{-1}$ penicillin-streptomycin at $37{ }^{\circ} \mathrm{C}\left(5 \% \mathrm{CO}_{2}\right)$. Moreover, $5 \times 10^{3}$ cells per well were seeded in 96-well plate and incubated for $24 \mathrm{~h}$. Then, CuS-PPy nanoprisms with different concentrations were added. The viability of the cells was analyzed after incubation for $24 \mathrm{~h}$.

$0.5 \mathrm{~mL}$ aqueous CuS nanoprisms, PPy and CuS-PPy solution with different concentrations were respectively added in a $1 \times 1$ $\times 4 \mathrm{~cm}$ quartz cuvette cell. The solution was irradiated with a NIR diode laser (1064 nm) with different power densities and durations. The diameter of the laser spot was $0.2 \mathrm{~cm}$. The temperature increment was measured with an optical fiber thermometer at an interval of $15 \mathrm{~s}$.

\section{In vitro and in vivo photothermal imaging and ablation}

The MGC-803 cells were transfected with green fluorescent protein (GFP). Then, the cells were seeded into 96-well plates and incubated for $24 \mathrm{~h}$. CuS-PPy nanoprisms with different concentration were added into each well. After $24 \mathrm{~h}$ of incubation, the cells were irradiated by a $1064 \mathrm{~nm}$ laser with an output power density of $1.0 \mathrm{~W} \mathrm{~cm}^{-2}$ for different times.

MGC-803 cells were inoculated into the nude mice. After the tumor length reached $0.5 \mathrm{~mm}$, the mice were intratumorally injected with the PBS solution of CuS-PPy nanoprisms $(100 \mu \mathrm{L}$, $\left.1 \mathrm{mg} \mathrm{mL}^{-1}\right)$ and PBS $(100 \mu \mathrm{L})$ respectively. After $24 \mathrm{~h}$, the tumor was irradiated with a $1064 \mathrm{~nm}$ laser with an output power density of $1.0 \mathrm{~W} \mathrm{~cm}^{-2}$ for $6 \mathrm{~min}$. Nude mice were obtained from the Shanghai LAC Laboratory Animal Co. Ltd. and Chinese Academy of Sciences (Shanghai, China, SCXK2007-0005). All animal experiments were conducted in compliance with 
institutional guidelines and approved by the Institutional Animal Care and Use Committee of Shanghai Jiao Tong University.

\section{Characterization}

UV-Vis-NIR absorption spectra were carried out with a Varian Cary 500 spectrophotometer. Transmission electron microscopy (TEM) images were taken on a Hitachi H-800 electron microscope and JEM-2100F microscopes at an acceleration voltage of $200 \mathrm{kV}$ with a CCD camera. The fluorescent images were obtained by a NIKON TS100-F fluorescence microscope. The temperature was measured by Fisher Scientific 14-648-12 thermometer. The infrared images of mice were obtained by a Testo 869 thermal imaging camera. The tumor size was measured by digital vernier caliper.

\section{Results and discussion}

CuS nanoprisms were synthesized as mentioned in the experimental. $\mathrm{Cu}\left(\mathrm{NO}_{3}\right)_{2}$ and $\mathrm{S}$ powder were mixed in oleylamine and 1-octadecene solution and reacted at $140{ }^{\circ} \mathrm{C}$ for $45 \mathrm{~min}$ to obtain CuS nanoparticles as 1st-generation seeds. Then, the 1stgeneration seeds were added into the growth solution of $\mathrm{Cu}\left(\mathrm{NO}_{3}\right)_{2}$ dissolved in oleylamine and 1-octadecene solution. The mixture was reacted under stirring at $120{ }^{\circ} \mathrm{C}$ for $60 \mathrm{~min}$ to get second-generation seeds, which were produced for the next growth. Comparing the morphologies of CuS nanomaterials prepared through different growth times (ESI, Fig. S1 $\dagger$ ), the CuS nanoprisms were obtained with desired size and structure after two growth cycles. As shown in Fig. 1a, the CuS nanoprisms were a triangular nanoplate. The average edge length was $19.2 \mathrm{~nm}$ (Fig. 1b), and the thickness was $4.8 \mathrm{~nm}$ (Fig. 1c). The lattice spacing of the CuS triangular face was $0.329 \mathrm{~nm}$, corresponding to the CuS (covellite) disk-like particles (Fig. 1d). ${ }^{61-63}$ (a)

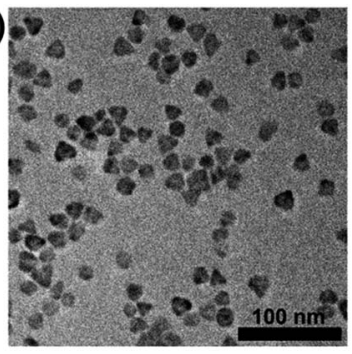

(c)

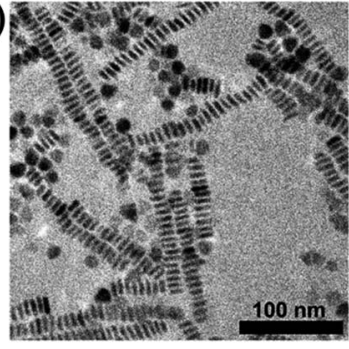

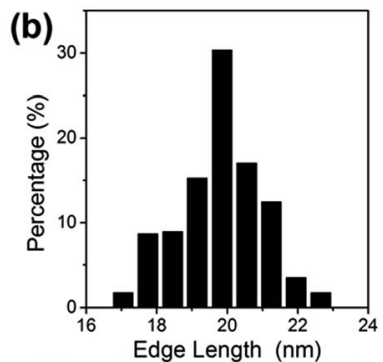

(d)

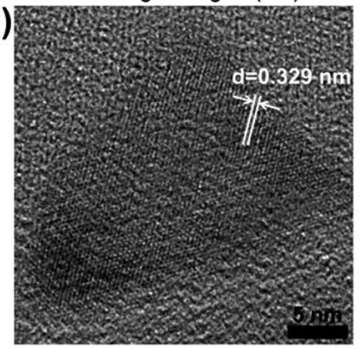

Fig. 1 TEM images of CuS nanoprisms ( $a$ and c), edge length distribution of CuS nanoprisms (b) and HRTEM image of the top-facet of a single CuS (d).

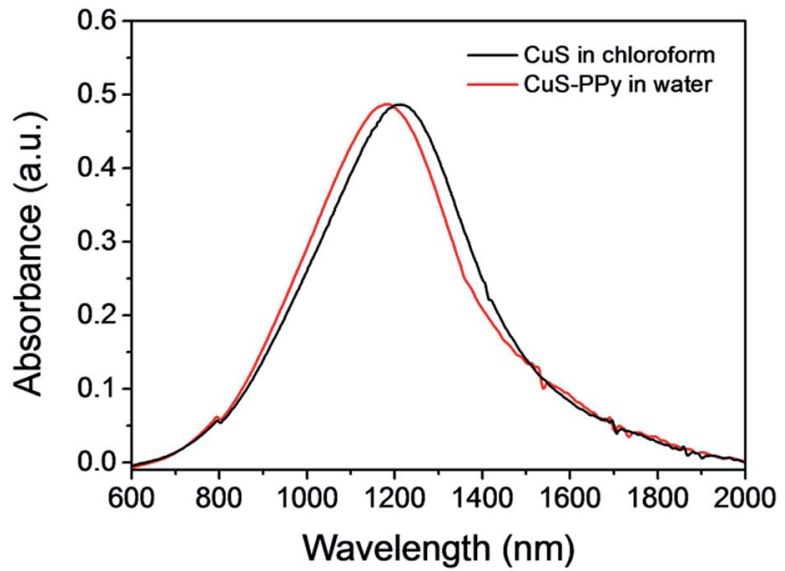

Fig. 2 The UV-Vis absorption spectra of CuS nanoprisms in the organic phase (black solid line), and transformed into the aqueous phase and modified with a PPy shell (red dash line).

The XRD pattern of CuS nanoprisms indicated that the peaks were consistent with those of the hexagonal CuS covellite phase (Fig. S2 $\dagger$ ). No diffraction peaks related to other $\mathrm{Cu} / \mathrm{S}$ ratio were observed, confirming the formation of the hexagonal CuS covellite phase. UV-Vis-NIR absorption of CuS nanoprisms displayed a peak at $1184 \mathrm{~nm}$ (black solid line), attributed to an inplane dipolar LSPR mode (Fig. 2). In general, the LSPR bond shift results from the change of size and aspect ratio. ${ }^{64}$ The CuS nanoprisms with high truncations and aspect ratio displayed more distinct plasmon resonance in the NIR region comparing with those of nanorods, nanocubes, or nanospheres.

To improve the hydrophilicity and structure stability in biological applications, the CuS nanoprisms were transferred to the aqueous phase and coated with a PPy shell on the surface through oxidative polymerization utilizing $\left(\mathrm{NH}_{4}\right)_{2} \mathrm{~S}_{2} \mathrm{O}_{8}$ as an initiator. During the phase transfer, SDS was added as the surfactant and absorbed onto the CuS nanoprisms by electrostatic interactions. Then, the pyrrole molecules could directly polymerize on the CuS surface based on the SDS existence. Fig. 2 shows the UV-Vis-NIR absorption spectra of CuS nanoprisms in chloroform and CuS-PPy in water. The slight red shift in UV-Vis-NIR absorption spectra may be attributed to the formation of the core-shell structure because the PPy shell influences the localized electric field distribution of CuS. ${ }^{65}$ Herein, the nontoxic PPy shell efficiently facilitated the hydrophilicity of CuS-PPy nanostructures. The colloidal stability of CuS-PPy nanoprisms and SDS-capped CuS nanoprisms in different medium are compared in Fig. S3. $\uparrow$ The photographs of CuS-PPy nanoprisms display that no aggregation appeared in water, saline, and PBS solution after one weak, but the SDScapped CuS nanoprisms precipitated in saline and PBS solution. This indicated that modifying the PPy shell improved the colloidal stability of nanoprisms. The coating of PPy shell was necessary for CuS nanoprisms to be used in further imaging and therapy.

The photothermal conversion performance of CuS-PPy nanoprisms was evaluated by measuring the temperature variation under the NIR laser irradiation. As shown in Fig. 3a, the 

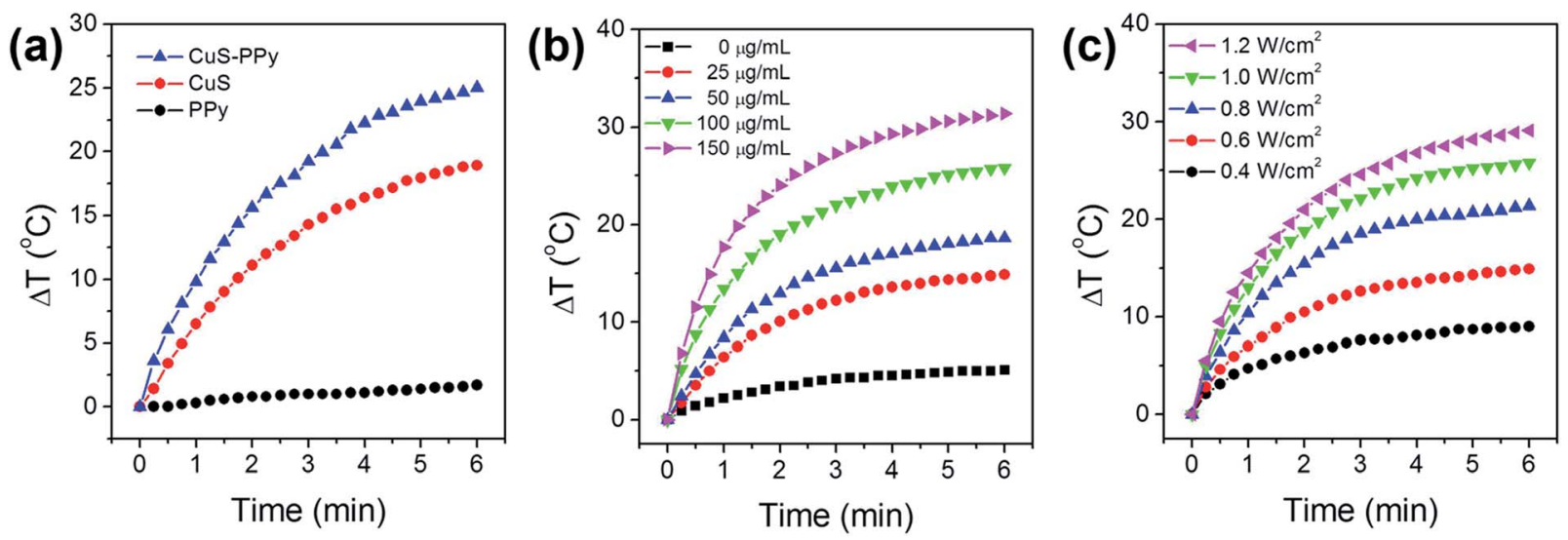

Fig. 3 (a) Temperature increment of CuS nanoprisms, PPy and CuS-PPy nanoprisms with same concentration under $1064 \mathrm{~nm}$ laser irradiation at $1.0 \mathrm{~W} \mathrm{~cm}^{-2}$, (b) temperature increment of CuS-PPy nanoprisms with different concentration under $1064 \mathrm{~nm}$ laser irradiation at $1.0 \mathrm{~W} \mathrm{~cm}{ }^{-2}$, (c) temperature increment of $100 \mu \mathrm{g} \mathrm{mL} \mathrm{L}^{-1}$ CuS-PPy nanoprisms with different laser density.

temperature increments of $0.5 \mathrm{~mL}$ PPy, CuS and CuS-PPy nanoprisms were monitored under $1064 \mathrm{~nm}$ laser irradiation

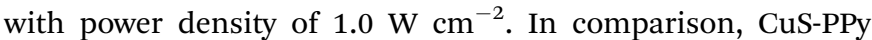
nanoprisms possessed a higher temperature increment than that of the CuS nanoprisms at the same concentration. This indicates that the coating of PPy shell is clearly beneficial to the NIR photothermal conversion. ${ }^{55,56}$ Fig. $3 \mathrm{~b}$ compares the temperature change of $0.5 \mathrm{~mL}$ CuS-PPy nanoprisms solution with the concentration varying from $25 \mu \mathrm{g} \mathrm{mL} \mathrm{L}^{-1}$ to $150 \mu \mathrm{g} \mathrm{mL}$ under the $1064 \mathrm{~nm}$ laser irradiation with a power density of $1.0 \mathrm{~W} \mathrm{~cm}^{-2}$. The temperature rose evidently in 2 minutes from $14.8{ }^{\circ} \mathrm{C}$ to $31.4{ }^{\circ} \mathrm{C}$. This was caused by the collective heating effect of the solution with a high nanomaterials concentration. ${ }^{66,67} \mathrm{NIR}$ light was absorbed and converted into heat much more due to the higher nanomaterials concentration. The laser irradiation density also influenced the temperature increment of CuS-PPy nanoprisms. With the increase of laser density from $0.4 \mathrm{~W} \mathrm{~cm}^{-2}$ to $1.2 \mathrm{~W} \mathrm{~cm}^{-2}$, the temperature of the $100 \mu \mathrm{g} \mathrm{mL}^{-1}$ CuS-PPy solution rose evidently from $9.0^{\circ} \mathrm{C}$ to $29.1^{\circ} \mathrm{C}$ (Fig. 3c). Therefore, the appropriate CuS-PPy concentration and laser irradiation density could be chosen to control the temperature between $42{ }^{\circ} \mathrm{C}$ and $47{ }^{\circ} \mathrm{C}$ to induce cell death and realize the efficiency of cancer photothermal therapy ${ }^{68,69}$ Furthermore, the photothermal stability of the CuS-PPy nanoprisms was evaluated through five cycles of on-and off laser irradiation. CuS-PPy nanoprisms solution was irradiated with a $1064 \mathrm{~nm}$ laser for $6 \mathrm{~min}$ and cooled to room temperature naturally. The temperature evolution during the five cycles is reported in Fig. S4a. $\dagger$ In comparison, the temperature increment has no evident decrease. Then, the UV-Vis-NIR absorption spectra of CuS-PPy nanoprisms before and after five cycles were characterized (Fig. S4b†). The absorption peak was retained well and no evident change appeared. The results demonstrated that the CuS-PPy nanoprisms possessed good NIR photothermal stability.

The cytotoxicity of nanomaterials is the primary limit of in vivo photothermal therapy. The cell viability of CuS-PPy nanoprisms was investigated using an MTT assay. Gastric cancer
MGC-803 cells were incubated in the culture media in the presence of different concentrations of CuS-PPy nanoprisms for $24 \mathrm{~h}$. As shown in Fig. 4, cell viability was more than $90 \%$ until the concentration of CuS-PPy nanoprisms reached to $150 \mu \mathrm{g}$ $\mathrm{mL}^{-1}$ and decreased to $86.4 \%$ with $200 \mu \mathrm{g} \mathrm{mL}{ }^{-1}$ CuS-PPy nanoprisms. For comparison, the cell viability decreased to $70.8 \%$ with $200 \mu \mathrm{g} \mathrm{mL} \mathrm{m}^{-1}$ SDS-capped CuS nanoprisms (Fig. S5 $\dagger$ ). This indicates that the SDS molecules were absorbed onto the nanoprism surface during the phase transform that exerted a toxic effect. When SDS-capped CuS nanoprisms were coated with nontoxic PPy on the outermost shell, the toxicity of nanoprisms was prominently decreased and the biocompatibility was effectively improved.

The photothermal performance of CuS-PPy nanoprisms in vitro was evaluated by irradiating the gastric cancer cells in the presence of CuS-PPy nanoprisms. The GFP-transfected gastric cancer cells were incubated with $100 \mu \mathrm{g} \mathrm{mL}^{-1}$ CuS-PPy nanoprisms under laser irradiation for $0 \mathrm{~min}, 1 \mathrm{~min}$ and $6 \mathrm{~min}$. Herein, the same irradiation location was observed every time to

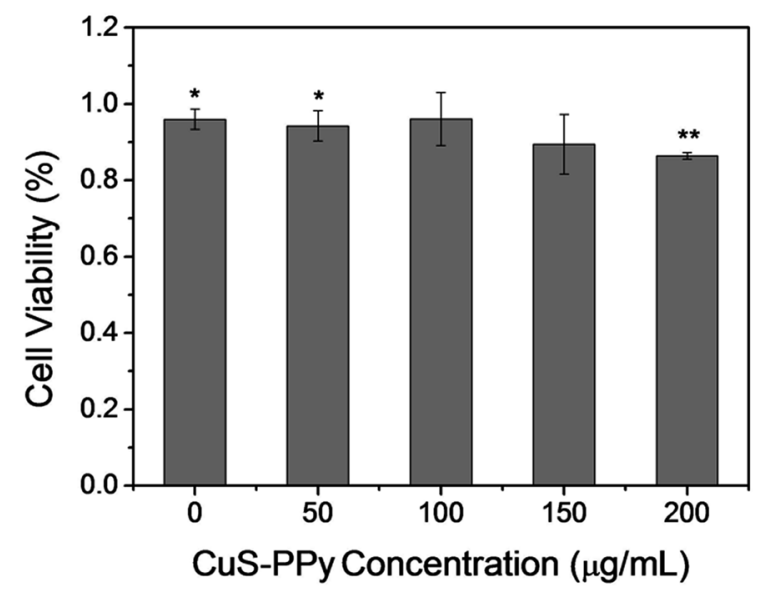

Fig. 4 Cytotoxicity of CuS-PPy nanoprisms with different concentrations by MTT assay. Data are shown as the means \pm standard error of the means, $* p<0.05$ and $* * p<0.01$. 

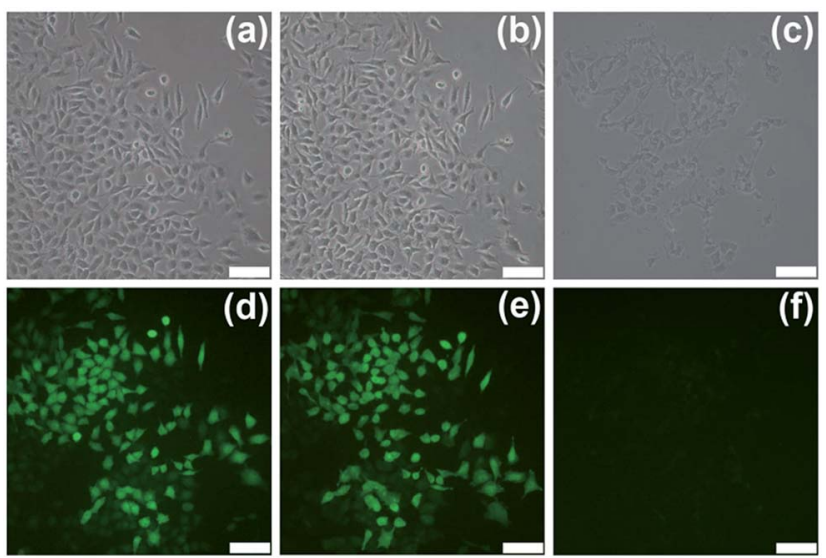

Fig. 5 Bright field images $(a-c)$ and fluorescent images $(d-f)$ of GFPtransfected cancer cells filled with $100 \mu \mathrm{g} \mathrm{mL}^{-1}$ CuS-PPy nanoprisms after irradiation by a $1064 \mathrm{~nm}$ laser for $0 \mathrm{~min}, 1 \mathrm{~min}, 6 \mathrm{~min}$. The scale bar is $50 \mu \mathrm{m}$.

compare the change of gastric cancer cells (Fig. 5). After $1 \mathrm{~min}$ irradiation, a part of cells began to shrivel as dots instead of attaching on the plate (Fig. $5 \mathrm{~b}$ and e). The temperature was not high enough to kill the cells at this time. With extending the irradiation time to $6 \mathrm{~min}$, the cancer cells were ablated and green fluorescence of live cells disappeared (Fig. 5c and f), indicating that the cancer cells in the irradiation spot were killed effectively. The results illustrate that the CuS-PPy nanoprisms could promote the cancer cells ablation efficiently under NIR laser irradiation.

Subsequently, photothermal therapy was carried out in vivo. $100 \mu \mathrm{L}$ of PBS solution of $1 \mathrm{mg} \mathrm{mL} \mathrm{mL}^{-1} \mathrm{CuS}$-PPy nanoprisms and $100 \mu \mathrm{L}$ PBS were respectively injected intratumorally into the

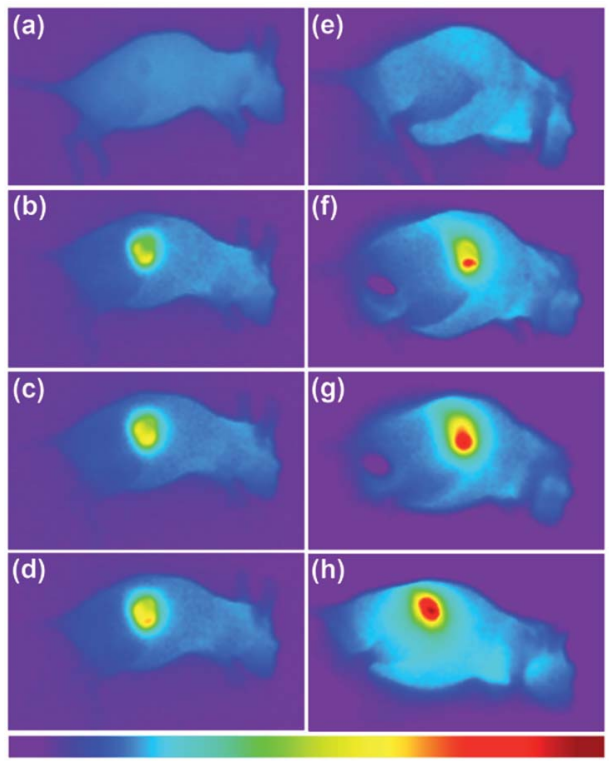

Fig. 6 Infrared thermal images of tumor-bearing mice treated without $(\mathrm{a}-\mathrm{d})$ and with (e-h) CuS-PPy nanoprisms $\left(1 \mathrm{mg} \mathrm{mL}^{-1}\right)$ under $1064 \mathrm{~nm}$ laser irradiation at different time intervals $(0,120,240$, and $360 \mathrm{~s})$. The scale bar of temperature is from $27^{\circ} \mathrm{C}$ to $55^{\circ} \mathrm{C}$. (a)

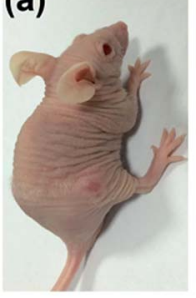

(b)

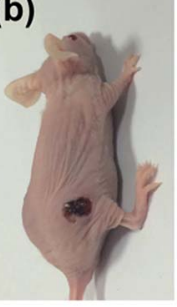

(c)

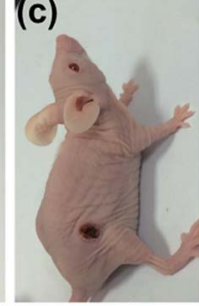

(d)

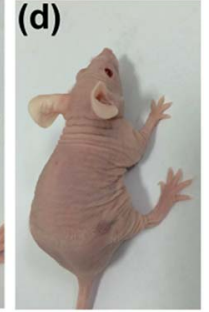

Fig. 7 Photographs of the tumor-bearing mice treated with CuS-PPy nanoprisms under laser irradiation, (a) before irradiation, (b) after 3 days, (c) after 11 days, and (d) after 18 days.

nude mice bearing MGC-803 tumor model. The tumor regions were irradiated under a $1064 \mathrm{~nm}$ laser for $6 \mathrm{~min}$. As shown in Fig. 6, the temperature of tumor injected with PBS increased slightly and remained below $40{ }^{\circ} \mathrm{C}$. The tumor temperature with CuS-PPy nanoprisms increased rapidly and reached $55{ }^{\circ} \mathrm{C}$ (Fig. S6 $\dagger$ ). The local high temperature of the tumor region with the assistance of CuS-PPy nanoprisms was able to kill the tumor cells effectively instead of damaging the healthy tissue severely. Then, the tumor volume was measured every day after the photothermal treatment. The growth of tumor injected with CuS-PPy nanoprisms under laser irradiation was inhibited effectively and the tumor disappeared after 18 days (Fig. 7). For comparison, the tumor volume injected with PBS grew from $0.09 \mathrm{~cm}^{3}$ to $0.6 \mathrm{~cm}^{3}$. This indicates that the CuS-PPy nanoprisms possessed excellent photothermal therapy efficacy and could be used for in vivo photothermal therapy.

\section{Conclusion}

In conclusion, we employed aqueous CuS-PPy nanoprisms as hyperthermia agents for photothermal therapy. Through the seed-mediated growth method, CuS nanoprisms were synthesized to obtain a triangle nanoplate morphology with intense NIR absorption property. Then, the CuS nanoprisms were transferred to the aqueous phase and coated with a PPy shell on the surface through oxidative polymerization to improve the hydrophilicity and structure stability. The PPy shell encapsulation efficiently decreased the cytotoxicity caused by the surfactant and increased the nanocomposite biocompatibility in the biological application. The CuS-PPy nanoprisms exhibited good photothermal conversion performance and possessed evident treatment effects on the tumor. It is promising to use CuS-PPy nanoprisms as an efficient theranostic agent for tumor photothermal therapy in the future.

\section{Acknowledgements}

This study was supported by National Natural Scientific Foundation of China (No. 51372125, 51572136, 21571112), China Postdoctoral Science Foundation (2015M570368), Natural Science Foundation of Shandong Province, China (ZR2016BQ28), and the Scientific Research Foundation of Qingdao University of Science and Technology. 


\section{Notes and references}

1 P. G. Morris and A. B. Lassman, Nat. Rev. Clin. Oncol., 2010, 7, 428-430.

2 F. M. Kievit and M. Zhang, Acc. Chem. Res., 2011, 44, 853-862.

3 D. A. Gewirtz, M. L. Bristol and J. C. Yalowich, Curr. Opin. Invest. Drugs, 2010, 11, 612-614.

4 R. Tian, J. Chen and R. F. Niu, Nanoscale, 2014, 6, 3474-3482.

5 M. C. Chen, Z. W. Lin and M. H. Ling, ACS Nano, 2016, 10, 93-101.

6 L. Y. Zeng, Y. W. Pan, S. J. Wang, X. Wang, X. M. Zhao, W. Z. Ren, G. M. Lu and A. G. Wu, ACS Appl. Mater. Interfaces, 2015, 7, 16781-16791.

7 J. R. Melamed, R. S. Edelstein and E. S. Day, ACS Nano, 2015, 9, 6-11.

8 Z. J. Zhang, J. Wang, X. Nie, T. Wen, Y. L. Ji, X. C. Wu, Y. L. Zhao and C. Y. Chen, J. Am. Chem. Soc., 2014, 136, 7317-7326.

9 X. J. Song, H. Gong, S. N. Yin, L. Cheng, C. Wang, Z. W. Li, Y. G. Li, X. Y. Wang, G. Liu and Z. Liu, Adv. Funct. Mater., 2014, 24, 1194-1201.

10 J. H. Park, G. von Maltzahn, M. J. Xu, V. Fogal, V. R. Kotamraju, E. Ruoslahti, S. N. Bhatia and M. J. Sailor, Proc. Natl. Acad. Sci. U. S. A., 2010, 107, 981-986.

11 S. K. Cho, K. Emoto, L. J. Su, X. Yang, T. W. Flaig and W. Park, J. Biomed. Nanotechnol., 2014, 10, 1267-1276.

12 P. K. Jain, X. Huang, I. H. El-Sayed and M. A. El-Sayed, Acc. Chem. Res., 2008, 41, 1578-1586.

13 A. Espinosa, R. D. Corato, J. Kolosnjaj-Tabi, P. Flaud, T. Pellegrino and C. Wilhelm, ACS Nano, 2016, 10, 24362446.

14 D. Jaque, M. L. Martínez, D. del Rosal, P. Haro-Gonzalez, A. Benayas, J. L. Plaza, E. Martín Rodríguez and J. GarcíaSolé, Nanoscale, 2014, 6, 9494-9530.

15 J. Bai, Y. W. Liu and X. Jiang, Biomaterials, 2014, 35, 58055813.

16 X. Y. Bu, D. Zhou, J. Li, X. Zhang, K. Zhang, H. Zhang and B. Yang, Langmuir, 2014, 30, 1416-1423.

17 L. Wang, RSC Adv., 2016, 6, 82596-82615.

18 J. M. Luther, P. K. Jain, T. Ewers and A. P. Alivisatos, Nat. Mater., 2011, 10, 361-366.

19 T. X. Wei, Y. F. Liu, W. J. Dong, Y. Zhang, C. Y. Huang, Y. Sun, X. Chen and N. Dai, ACS Appl. Mater. Interfaces, 2013, 5, 10473-10477.

20 X. Liu and M. T. Swihart, Chem. Soc. Rev., 2014, 43, 39083920.

21 J. Mou, C. B. Liu, P. Li, Y. Chen, H. X. Xu, C. Y. Wei, L. Song, J. L. Shi and H. R. Chen, Biomaterials, 2015, 57, 12-21.

22 Q. F. Xiao, X. P. Zheng, W. B. Bu, W. Q. Ge, S. J. Zhang, F. Chen, H. Y. Xing, Q. G. Ren, W. P. Fan, K. L. Zhao, Y. Q. Hua and J. L. Shi, J. Am. Chem. Soc., 2013, 135, 13041-13048.

23 Q. W. Tian, M. H. Tang, Y. G. Sun, R. J. Zou, Z. G. Chen, M. F. Zhu, S. P. Yang, J. L. Wang, J. H. Wang and J. Q. Hu, Adv. Mater., 2011, 23, 3542-3547.
24 M. Zhou, R. Zhang, M. A. Huang, W. Lu, S. L. Song, M. P. Melancon, M. Tian, D. Liang and C. Li, J. Am. Chem. Soc., 2010, 132, 15351-15358.

25 S. W. Hsu, K. On and A. R. Tao, J. Am. Chem. Soc., 2011, 133, 19072-19075.

26 M. Liu, X. Xue, C. Ghosh, X. Liu, Y. Liu, E. P. Furlani, M. T. Swihart and P. N. Prasad, Chem. Mater., 2015, 27, 2584-2590.

27 A. Dutta and S. K. Dolui, Mater. Chem. Phys., 2008, 112, 448452.

28 X. Dong, D. Potter and C. Erkey, Ind. Eng. Chem. Res., 2002, 41, 4489-4493.

29 X. B. Wang, C. Q. Xu and Z. C. Zhang, Mater. Lett., 2006, 60, 345-348.

30 X. H. Liao, N. Y. Chen, S. Xu, S. B. Yang and J. J. Zhu, J. Cryst. Growth, 2003, 252, 593-598.

31 Q. Y. Lu, F. Gao and D. Y. Zhao, Nano Lett., 2002, 2, 725-728. 32 C. H. Tan, Y. L. Zhu, R. Lu, P. C. Xue, C. Y. Bao, X. L. Liu, Z. P. Fei and Y. Y. Zhao, Mater. Chem. Phys., 2005, 91, 44-47. 33 Y. C. Chen, J. B. Shi, C. Wu, C. J. Chen, Y. T. Lin and P. F. Wu, Mater. Lett., 2008, 62, 1421-1423.

34 Y. H. Ni, R. Liu, X. F. Cao, X. W. Wei and J. M. Hong, Mater. Lett., 2007, 61, 1986-1989.

35 C. H. Tan, R. Lu, P. C. Xue, C. Y. Bao and Y. Y. Zhao, Mater. Chem. Phys., 2008, 112, 500-503.

36 W. M. Du, X. F. Qian, X. D. Ma, Q. Gong, H. L. Cao and J. Yin, Chem.-Eur. J., 2007, 13, 3241-3247.

37 Y. S. Liu, D. H. Qin and L. Y. Cao, Mater. Chem. Phys., 2007, 102, 201-206.

38 S. Gorai, D. Ganguli and S. Chaudhuri, Cryst. Growth Des., 2005, 5, 875-877.

39 T. Thongtem, A. Phuruangrat and S. Thongtem, Curr. Appl. Phys., 2009, 9, 195-200.

40 L. J. Sherry, R. Jin, C. A. Mirkin, G. C. Schatz and R. P. Van Duyne, Nano Lett., 2006, 6, 2060-2065.

41 E. Hao and G. C. Schatz, J. Chem. Phys., 2004, 120, 357-366.

42 K. H. Lee, Q. L. Chen, C. H. Yip, Q. Yan and C. C. Wong, Microelectron. Eng., 2010, 87, 1941-1944.

43 H. Chen, X. Kou, Z. Yang, W. Ni and J. Wang, Langmuir, 2008, 24, 5233-5237.

44 X. B. Xu, Z. Yi, X. B. Li, Y. Y. Wang, J. P. Liu, J. S. Luo, B. C. Luo, Y. G. Yi and Y. J. Tang, J. Phys. Chem. C, 2013, 117, 17748-17756.

45 J. E. Millstone, W. Wei, M. R. Jones, H. J. Yoo and C. A. Mirkin, Nano Lett., 2008, 8, 2526-2529.

46 T. H. Ha, H. J. Koo and B. H. Chung, J. Phys. Chem. C, 2007, 111, 1123-1130.

47 G. S. Metraux and C. A. Mirkin, Adv. Mater., 2005, 17, 412415.

48 Y. X. Zhao, H. C. Pan, Y. B. Lou, X. F. Qiu, J. J. Zhu and C. Burda, J. Am. Chem. Soc., 2009, 131, 4253-4261.

49 W. Lou, M. Chen, X. Wang and W. Liu, J. Phys. Chem. C, 2007, 111, 9658-9663.

50 Y. Xie, L. Carbone, C. Nobile, V. Grillo, S. D'Agostino, F. Della Sala, C. Giannini, D. Altamura, C. Oelsner, C. Kryschi and P. D. Cozzoli, ACS Nano, 2013, 7, 7352-7369. 
51 C. Y. Wu, S. H. Yu, S. F. Chen, G. N. Liu and B. H. Liu, J. Mater. Chem., 2006, 16, 3326-3331.

52 H. T. Zhu, J. X. Wang and D. X. Wu, Inorg. Chem., 2009, 48, 7099-7104.

53 J. M. Fonner, L. Forciniti, H. Nguyen, J. D. Byrne, Y.-F. Kou, J. Syeda-Nawaz and C. E. Schmidt, Biomed. Mater., 2008, 3, 3750-3756.

54 C. L. Du, A. H. Wang, J. B. Fei, J. Zhao and J. B. Li, J. Mater. Chem. B, 2015, 3, 4539-4545.

55 J. Li, J. S. Han, T. S. Xu, C. R. Guo, X. Y. Bu, H. Zhang, L. P. Wang, H. C. Sun and B. Yang, Langmuir, 2013, 29, 7102-7110.

56 Q. W. Tian, Q. Wang, K. X. Yao, B. Y. Teng, J. Z. Zhang, S. P. Yang and Y. Han, Small, 2014, 10, 1063-1068.

57 Z. B. Zha, X. L. Yue, Q. S. Ren and Z. F. Dai, Adv. Mater., 2013, 25, 777-782.

58 K. Yang, H. Xu, L. Cheng, C. Y. Sun, J. Wang and Z. Liu, Adv. Mater., 2012, 24, 5586-5592.

59 M. Chen, X. L. Fang, S. H. Tang and N. F. Zheng, Chem. Commun., 2012, 48, 8934-8936.

60 Y. Tian, J. P. Zhang, S. W. Tang, L. Zhou and W. L. Yang, Small, 2016, 12, 721-726.
61 S.-W. Hsu, C. Ngo, W. Bryks and A. R. Tao, Chem. Mater., 2015, 27, 4957-4963.

62 H. Zhang, Y. Q. Zhang, J. X. Yu and D. R. Yang, J. Phys. Chem. C, 2008, 112, 13390-13394.

63 A. Ghezelbash and B. A. Korgel, Langmuir, 2005, 21, 94519456.

64 X. L. Wang and M. T. Swihart, Chem. Mater., 2015, 27, 17861791.

65 L. H. Tan, S. X. Xing, T. Chen, G. Chen, X. Huang, H. Zhang and H. Y. Chen, ACS Nano, 2009, 3, 3469-3474.

66 S. T. Wang, K. J. Chen, T. H. Wu, H. Wang, W. Y. Lin, M. Ohashi, P. Y. Chiou and H. R. Tseng, Angew. Chem., Int. Ed., 2010, 49, 3777-3781.

67 X. Zhang, X. W. Xu, T. T. Li, M. Lin, X. Y. Lin, H. Zhang, H. C. Sun and B. Yang, ACS Appl. Mater. Interfaces, 2014, 6, 14552-14561.

68 J. S. Han, J. J. Zhang, M. Yang, D. X. Cui and J. M. de la Fuente, Nanoscale, 2016, 8, 492-499.

69 C. Vauthier, N. Tsapis and P. Couvreur, Nanomedicine, 2011, 6, 99-109. 